\title{
Developing Headquarters Economy to boost urban transformation - - A Case Study of Wuhan City Circle
}

\author{
Min Yu, Li-hua Zhong \\ Department of Manufactory Development Research Center in Wuhan City Circle, Jianghan University, Hubei Province, China \\ yuminss@163.com, chengmoweidao@126.com
}

\begin{abstract}
In the era of rapid economic development, Urban transformation is necessary. The developing of urban transformation is a comprehensive, multi-level, multi-stage process. The key of urban transformation lies in developing economic, the development of headquarters economy not only take advantage of resources in large cities, but also help to provide a new connection to the central industrial city, which will help cities achieve economic transformation, enhance its radiation, promote coordinated regional development. From the perspective of headquarters economy, based on theory of the Relationship between Headquarters Economy and Regional economic, Wuhan city circle, as an example, pointed out the problem of the development of Wuhan city circle, and the headquarters economy as a new model of Regional economic development, can effectively break the administrative regional planning restrictions, to connect Wuhan with the surrounding satellite cities. And some targeted suggestions on how to promote economic development with headquarters in Wuhan city circle construction will be given.
\end{abstract}

Index Terms - countermeasures, headquarters economy, Wuhan city circle, urban transformation

\section{Situation Analysis and the Existing Problem of Urban Development in Wuhan City Circle}

In recent years, all aspects of Wuhan city circle have made great achievements. But as the situation changes, the Wuhan city circle want to get further development, facing a series of problems, such as All aspects of the gap between Wuhan and surrounding cities is growing, in industrial development, there are some similarity phenomenon between cities on market positioning, resulting in a lack of effective cooperation among the nine cities. some of the previous practical experience of Headquartered economic development at home and abroad repeatedly verified a theory: the headquarters economic model and the urban agglomeration development is mutually beneficial [1]

\section{A. It's fatigue to improve the total proportion of city circle economies accounted for the province.}

From figure one, In the first three quarters of 2012, the Wuhan city circle realized GDP of 845.129 billion, with yearon-year growth of $13.3 \%$, Fell 2 percent increase over last year. City circle occupy the province's GDP increased by 1.7 percentage points over the same period last year, reaching $62.2 \%$, due to the Slowdown in economic growth of Wuhan. the growth rate of Wuhan city circle overall increase 0.7 percentage points lower than the provincial. A decline in economic output growth, Growth is lower than the provincial average level. View from the city .in the first three quarters, Wuhan city reached GDP of 492.522 billion, accounting for $58.23 \%$ in City Circle. Therefore, the status of the central city of Wuhan is particularly evident.

With the improving of Xiangyang and Yichang cities' economic status in province, Wuhan city circle comprehensive economic strength needs to be further strengthened [2].

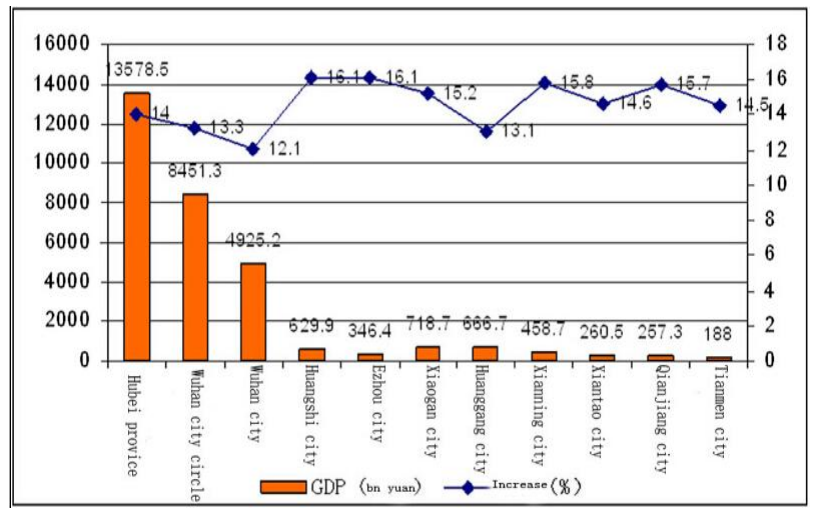

Fig. 1 the growth of GDP for the first three quarters of Hubei Province and Wuhan City Circle in 2012

Source: Hubei Provincial Bureau of Statistics Yearbook Quarterly Report (2012)

\section{B. Industries have been expanding, but just started new industrialization}

From the City Circle industrial structure, the Wuhan city circle representing the proportion of the industrial economy has declined, presenting "diversification" trend. From January to October in 2011, Wuhan accumulated above-scale industrial added value of 201.701 billion, accounting for 52 percent in urban proportion circle, down one percentage point over the first half year, down 3.9 percentage points over the same period last year. The calculated value of the industrial economy is also reflected this trend.

With the advance of "two-oriented society" Reform and development of new industrialization, the development of Wuhan city circle encountered a "bottleneck." Specifically in the following areas:

1) First, the industrial system structure is irrational, the existing industrial system of Wuhan city circle is so huge [3]. The structure is not appropriate, having a relatively large 
proportion of heavy industry, economic growth is still dependent on the secondary industry.

2)Second, with the "two-oriented society" made and construction, Wuhan city circle has started to move towards the direction of new industrialization, which also introduced some measures, such as a green industrial development planning of wuhan. But there is no fundamental change in the industrial structure, in 2011, the heavy industry in Wuhan city circle accounting for $70 \%$, while the primary industry and tertiary industry proportion is very low, especially in modern logistics, electricity providers, service sector. enhance the proportion of tertiary industry is imminent, second industrial development has brought more and more. serious environmental problems, abnormal weather in 2013, the emergence of highly polluted haze indicates that industrial structure must be effectively adjusted.

\section{Investment growth slowed, the economic stimulus effect gradually weaken}

On November of 2008, under global financial crisis, China launched the "four trillion" economic stimulus plan, along with housing projects, water projects, health care, transportation and other infrastructure construction started, in order to stabilize the economy, Since then, the growth of investment in fixed assets faster and faster, but since 2012, the stimulating effect gradually weakened, the investment growth rate began to decline. Wuhan City Circle investment growth fell to 30.6 percent in 2010 from 2009's $39.9 \%$. There presents a further downward trend in 2012.

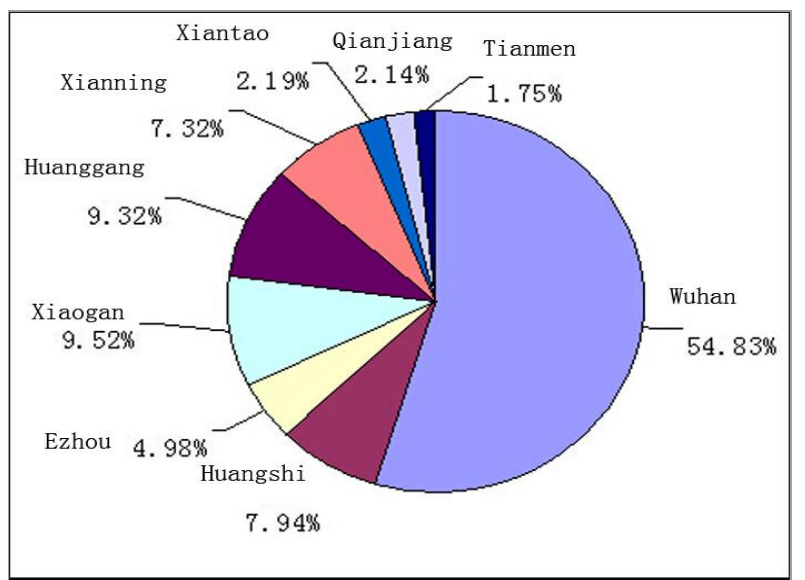

Fig. 2 the Proportion of GDP about nine cities of Wuhan City Circle in 2012 Source: Hubei Provincial Bureau of Statistics Yearbook Quarterly Report (2012)

\section{The gap between urban circle continues to expand, the overall linkage should be improved}

According to the Hubei Provincial Bureau Statistical Yearbook of city circle "two-oriented society", in 2012, Wuhan is in first place of nine cities above key industries, GDP was 800.382 billion, ranking first, the rate of increase over the previous year for $11.4 \%$, accounting for 57.7 percent of urban proportion circle; including industrial added value, fixed asset investment, retail sales ,foreign investment., Wuhan in the rankings are the first circle in this five economic indicators, the development gap between the cities of Wuhan city circle is huge, and continues to expand.

\section{E. The policy system need to be further refined}

The "Two-oriented society" of Wuhan city Circle progressed smoothly, with remarkable results, but when it comes to institutional reform within the region and enter the implementation stage, It's difficult to fully implement the reform objectives and tasks by supporting policies described above, metropolitan development thrust is clearly insufficient [4].

\section{Theory of the Relationship between Urban Restructuring and Headquarters Economic}

\section{A. The perspective of the basic theory}

"Headquartered Economic" theory mentioned, Headquarters economy, an important part of the regional economic development, is establishing a new theoretical system at the basis of the effective integration of enterprise value chain theory and regional economic theory, as a regional economic development strategy expand and deepen.

\section{B. The perspective of long-term development perspective}

Headquarters economy, as a new development model, can narrow the gap between cities of Wuhan city circle about regional economic development, for example, Corporate headquarters can be concentrated in Wuhan, The heavy industry of Huangshi City is in first place of nine cities, so the base of heavy industry can be built in Huangshi city, which helps to balance development of nine cities.

\section{The perspective of the development of a realistic look}

Headquarters economy is the core power to promote regional economic transformation [4]. Headquarters economy is essentially a high-end service economy, you can attract more resources in the region, a large number of group headquarters will toward the central city, creating a growth pole of regional development.

\section{The Strategies of Headquarters Economy to Boost Urban Transformation}

Developing headquarters economy is not only inevitable choice for" Two -oriented society" long-term development, but also an inevitable choice for innovative development model breakthroughs. But standing in a realistic point of view, building the development model to the headquarters economy of Wuhan city circle, is not easy, requires innovation and change, need to invest huge human, material and financial resources, is the great complex systems engineering, so the scheduled start from all aspects.

A. Adhere to take Wuhan city as a core area of introducing the group headquarters.

First, Wuhan should play a good role of "big brother "; on one hand actively served the eastern advanced manufacturing 
industries to undertake the mission, occupy proactive role in optimizing the industrial division of labor [5]. At the same time What we should know that Wuhan is great in economy, but the land resources are very limited, it is impossible that all the manufacturing and high-tech industries are included in Wuhan plans, therefore, all kinds of industries should be shift the origin, From the new development positioning of Wuhan City, more focus should be placing on the goal of attracting the industry of external regional corporate headquarters, corporate marketing and R \& D headquarters settled.

\section{B. Constructing "Headquarters - manufacturing base" industrial chain of city circle}

Wuhan manufacturing base should be gradual relocation, and part of the upcoming elimination of the traditional industries of corporate headquarters relocation in exchange for more land resources and surplus capital, and ultimately attract a higher level of advanced manufacturing headquarters settled in Wuhan. The eight cities should also be firmly based in Wuhan, as a good supporting production base of Wuhan, all kinds of advanced manufacturing and high-tech industries and traditional manufacturing industries to undertake appropriate corporate headquarters, and ultimately accelerate the industry agglomeration and industrial upgrading.

\section{Improve the environment}

Wuhan city circle should also be a clear direction, the main headquarters of promoting economic development in three aspects. First, through the construction of high-grade modern business office, promoting large companies gathered in Wuhan, Second, the modern society is the information age, information developed cities flaunt the level of modernization of a city. So accelerating the development of information technology is necessary, building the city and convenient information environment, Third, Transport is an urban development "track" Transportation issues to be resolved. Finally, Modern service industry is an iconic indicator of a city's comprehensive development stage positioning, so the establishment of professional service support system is particularly important.

\section{Strengthen government services}

Government services have been some obvious problems, such as government information platform is not perfect, the service attentive enough, inadequate legal and policy issues, so need to promote the deepening of the reform of government institutions. Construction should focus on solving the problems of government information and services platform to service government transformation. In policy formulation, policy should be more inclined to support and encourage scientific and technological progress, and promote new technologies. In the legal system, the city government should improve the intellectual property law and related corporate law, to create a good institutional environment for enterprise development, give full play to strong government oversight function effectively protect corporate $\mathrm{R} \& \mathrm{D}$ results.

\section{E. Developing manufacturing}

Manufacturing shift to the surrounding area, that can promote economic development of the surrounding area, providing industry support for the headquarters economy and avoid hollowing out of headquarters economy, but also make some space for the development of the city, better development of modern service industry, high-tech industries such as high-end industries, to provide support for the development of headquarters economy [5]. From the reality of the current development of Wuhan city circle, some large manufacturing industries in Wuhan should be transferred to eight neighboring cities having resource comparative advantage, to promote a balanced and healthy development of each city circle.

\section{F. Accelerate the development of modern service industry}

Modern service industry mainly include seven outsourcing producer services such as the development of modern logistics, technology services, information services, business services, financial services, marketing services [6]. Thus accelerating the development of modern service industry should start from the following aspects:

1) First, there is the orderly expansion of the financial services sector. Around the promotion of small and micro enterprise development, innovative financial products and services model, and promote the combination of banking and e-commerce era; improve the development of city circle of credit financing, securities, trust, wealth management, leasing, guarantees, net commercial bank such as asset allocation and financing services of various financial services; broaden insurance services, establish and improve the system of insurance services [7].

2) Second, developing third-party logistics is so important. Promotion of modern logistics management, improve logistics enterprises access, improve logistics practitioners treatment and enhance the quality. Fostering the growth of high-tech services, business services specification upgrade. Actively develop tourism.

\section{Conclusion}

This paper proposes to promote the development of headquarters economy through the cities of Wuhan city circle restructuring and development of the key development is the transformation of urban transformation of economic development, the development of headquarters economy conducive advantage of resources in large cities, but also help to provide a new industry for the center of the city continuation, which will help cities achieve economic transformation, driven by the ability to enhance its radiation, promoting coordinated regional development .

\section{References}

[1] Duan Haibo "Construction Mode of Headquarters Economy Zone," Beijing plans to build (January 2014)

[2] Luo Hongyi "the feature links between cities" Wuhan city circle," Chinese Market (March 2014) 
[3] Li Ling. Chou Fangdao Zhu Chuangeng and Ma Suisui. "Urban restructuring Progress and Prospects," Areal Research and Development (April 2012)

[4] Zhang Feixiang and Chen jinniang "Foreign trend of urban transformation and Experience," Enterprise economy (May 2011)
[5] Zhu Yaling and Zhang Baojun "New urban development pattern problem of Wuhan city circle," Yu Changjiang trespassing (May 2011)

[6] Song Rui "headquarters economy theory and systematic study," Chinese HowNet (August 2009)

[7] Liu Siwei and Xu Zhiyao. "The evolution and innovation of the economy development model, , Huxiang Forum (March 2013 ) 